\title{
PASTORES DE HUALLANCALLANE. LOS MÁRGENES DEL TERRITORIO Y LA SOCIEDAD NACIONAL EN LOS ALBORES DEL SIGLO XXI.
}

\author{
Huallancallane Pastoralists. The Margins of the Territory and the National Society \\ at the Beginning of the Twenty-First Century.
} JORGE MOREIRA * Y CRISTHIAN CERNA **

Fecha de recepción: 10 de marzo de 2017, Fecha de aprobación: 02 de mayo de 2017

\section{Resumen}

El artículo presenta el caso de una estancia altiplánica en la comuna de General Lagos, cuyos habitantes desarrollan la actividad pastoril como medio de subsistencia familiar, iterando entre la ciudad y el campo, para abordar el ámbito de la reproducción del sistema de pastoreo altiplánico en el extremo norte de Chile. Con esta base, desde datos etnográficos, se caracterizan aspectos de las transformaciones organizativas que experimentan estos pastores en un contexto histórico que imputa elementos de desestructuración a su forma de manejo socioambiental.

Palabras clave: altiplano, estancia huallancallane, comunidad sucesorial, sistema de pastoreo

\section{Abstract}

The article presents the case of a "estancia", that is an Andean traditional settlement frame at highland of northern Chile, whose inhabitants develop the camelid pastoralism activity as a means of family subsistence, to address the field of reproduction of this system. On this basis, founded on ethnographic data, we characterize the aspects of the organizational changes experienced by these herders in a historical context that impute elements of destructuring their traditional socio-environmental management.

Palabras clave: altiplano, huallancallane estancia, sucesoral community, pastoralism

* Licenciado en Historia, Universidad de Santiago de Chile. Magíster en Antropología, Universidad Academia de Humanismo Cristiano, Santiago, Chile. El artículo está enmarcado en una investigación para Conadi-Gobernación Provincial de Parinacota: "Estudio, confección y tramitación de regularización y/o transferencia de predios de uso comunitario a favor de la Comunidad Indígena". Correo-e: jorge.moreira.p@hotmail.com

**Antropólogo Social, Universidad de Tarapacá. Magíster en Ciencias Sociales, Universidad de Chile, Investigador principal del Centro de Investigaciones del Hombre en el Desierto (CIHDE), Arica, Chile. Correo-e: cristhiangcerna@gmail.com; ccerna@ cihde.cl 


\section{Introducción}

En los Andes, el pastoralismo ha sido considerado por la sociedad y por los estudios sociales como una forma marginal de vida, tanto por las condiciones geográficas en las que se desarrolla, por su particular inclusión a las lógicas de mercado, así como por su carácter eminentemente rural, en el contexto de los paradigmas de desarrollo y modernización que han configurado los territorios andinos (Flores, 1983; Göbel, 2002; Ossio, 1982; Salomon, 2012; Sendón, 2003, 2006, 2008, 2012). Sin embargo, diversos estudios demuestran que el pastoreo es una actividad sustentable vinculada a procesos de adaptación sociocultural en ecosistemas específicos y extremos, siendo la movilidad una estrategia necesaria para lograr un adecuado aprovechamiento de los recursos, en el marco de la precarización estructural de sus territorios, donde el Estado ha sido un principal actor de cambio social y de diferenciación de procesos históricos seguidos por las colectividades (Palomino, 2012; Postigo et al., 2008).

En el norte de Chile se ha seguido un proceso coherente con las agendas investigativas del área andina más general, con enfoques que involucran lecturas ecológicas, culturalistas, de campesinos y de agencia social del fenómeno. A partir de la década de 1970, desde un enfoque eco-culturalista, se ha documentando la actividad tradicional de subsistencia de los habitantes de la cuenca altiplánica y su compleja realización en el contexto de la amenaza de su ecosistema y relaciones comunitarias, las que mantendrían estrategias de doble vinculación con los proyectos de modernización regional, por un lado integrándose a los procesos más generales, y por otro reproduciendo su diferenciación colectiva en ámbitos socioeconómicos y simbólicos (Castro, 1997, 2006, 2014;
Gundermann, 1984,1998). En este sentido, las transformaciones estructurales ocurridas durante el transcurso del siglo XX han provocado importantes cambios en las poblaciones de base, revelándose nuevas formulaciones de estructuras familiares, que establecen cambios importantes en la constitución y reproducción del sistema de propiedad de la tierra. Esto, instado por la particular conexión socioeconómica de los grupos referentes, atendiendo a la tesis de marginal inserción en el mercado (la demanda de sus productos ganaderos, transacción -no monetaria o monetaria- y las lógicas de consumo subsecuente) y la fuga de contingentes, siguiendo un patrón histórico detectable desde mediados del siglo XX (Cerna \& Samit, 2013).

En su conjunto, el sistema pastoril ha decantado en un escenario con novedosos pliegues organizativos que requiere un análisis situacional, dando cuenta de sus reformulaciones ante la transformación de sus elementos configurantes. Dado aquello, vale considerar que la caracterización de estos problemas implica una reflexividad sobre cómo los pastores afrontan el diagnóstico de precarización de sus bases socioproductivas.

En este sentido, desde un enfoque de agencia social y ecológico, se revisa el caso etnográfico de la estancia de Huallancallane, entidad sucesorial del altiplano norte, en la Región de Arica y Parinacota. A propósito, se propone una reflexión sobre el sistema de pastoreo y su vigencia, que permite visualizar la capacidad de resiliencia de los grupos locales ante la imposición de criterios "externos" y de adaptación/reproducción de perspectivas locales de manejo medioambiental. 


\section{Caso etnográfico}

El territorio de Huallancallane se encuentra localizado en la comuna de General Lagos, Provincia de Parinacota, alrededor de $10 \mathrm{kms}$ al sur de Visviri. Emplazado en el sector "carre- tera" del altiplano, es un lugar atravesado por la principal vía de comunicación vehicular, la ruta A-93, que conecta con la carretera internacional hacia Bolivia o Arica, la ruta $11-\mathrm{CH}$.

Mapa 1. Localización del caso etnográfico

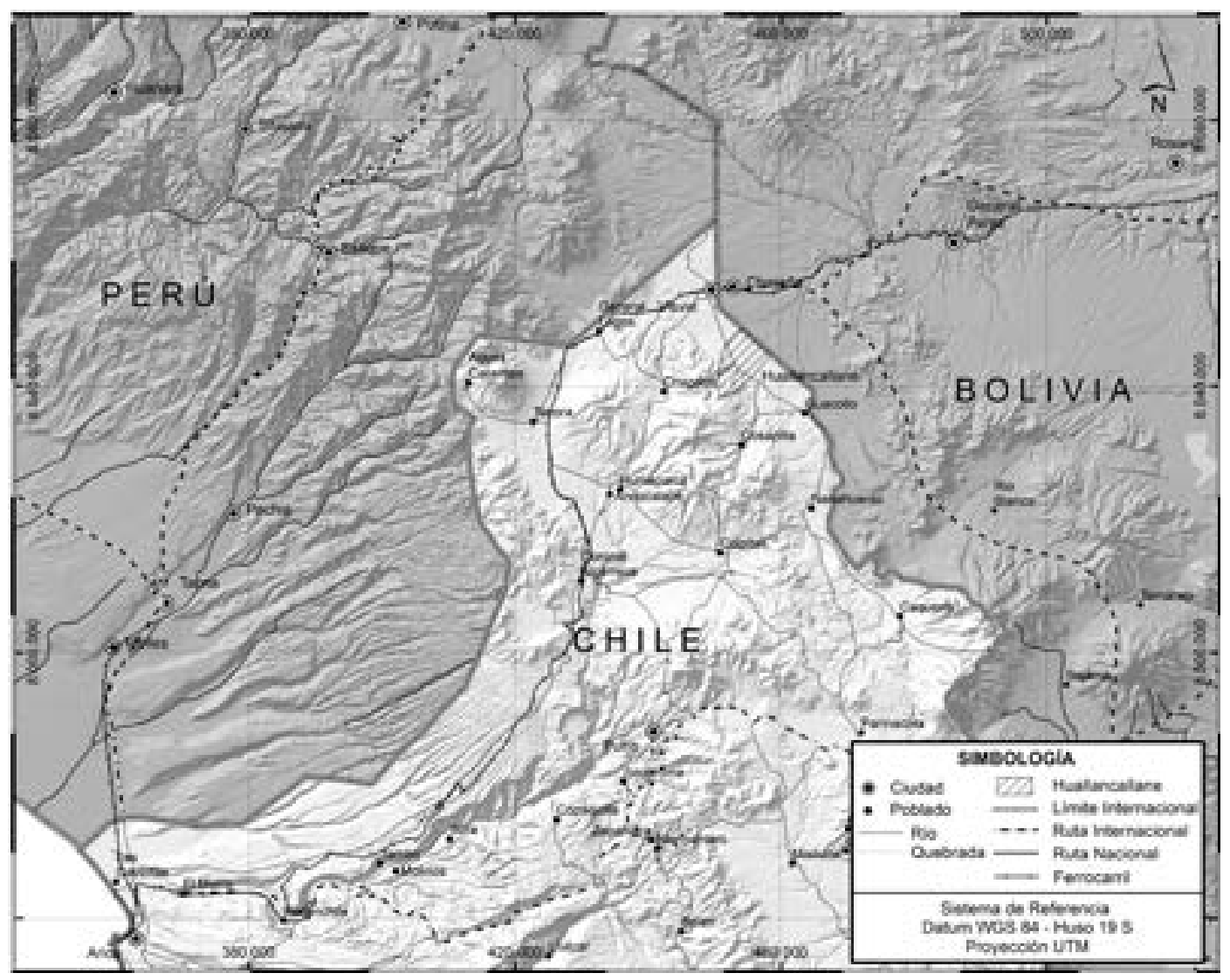

Fuente: Cerna, Samit \& Fradejas (2013). 
Esta estancia corresponde a una unidad territorial y social que aglutina a un conjunto de familias nucleares que ejercen derechos sobre la tierra mancomunadamente (Gundermann, 1984) ${ }^{1}$. De acuerdo a sus miembros, esta unidad habría sido escindida del antiguo ayllu de Cosapilla, a inicios del siglo XX, pueblo con el que sus habitantes todavía presentan relaciones de parentesco. La superficie total de la estancia es de 6.167,38 hectáreas. Sus deslindes son: por el noroeste limita con la estancia de Piasalla, por el noreste con la de Colpachuncho, al este con la frontera chileno-boliviana, al sur con la propiedad de Cruz Vilque, al oeste con la estancia de Putani.

El ecosistema del lugar corresponde a la puna seca (Núñez \& Dillehay, [1979] 1995), caracterizado por una altitud promedio de $4.000 \mathrm{msnm}$, amplia oscilación térmica, fuertes vientos, una estación seca prolongada y lluvias que se concentran los meses de verano, entre diciembre y febrero. Estas condiciones limitan las potenciales labores productivas, especialmente la incorporación de la agricultura, por lo que sus habitantes desarrollan exclusivamente la ganadería camélida.

Cabe precisar que el pastoreo no es solo la labor productiva de sus habitantes, sino que constituye una forma particular de vida en los Andes (Medinaceli, 2005; Tomasi, 2013). De acuerdo a las relaciones derivadas de esta actividad, los pastores han desarrollado manifestaciones culturales que les otorgan una identidad colectiva específica, en parte motivo por el cual hasta el día de hoy, a pesar de las dificultades coyunturales, mantienen su ganado con un pastoreo de tipo tradicional.

\section{Producción}

\section{Familia y comunidad}

A fines del siglo XIX, tras la Guerra del Pacífico, la nueva administración chilena redefinió el territorio del altiplano, así como el acceso a las tierras. Se exigió la inscripción de las tierras en los Registros Conservadores de Propiedad, instalados en las ciudades de Tacna y Arica, con el doble objetivo de permitir su transacción en el mercado y distinguir las tierras fiscales de las particulares, desde un principio que no reconocía la propiedad raíz de tipo colectiva (Cerna, Samit \& Fradejas, 2013; Castro, 2014; Díaz y Ruz, 2009; González \& Gundermann, 2009; González \& Ruz 2015; Ruz, 2009; Ruz \& González, 2014). Este proceso dio origen a la formación de las llamadas "comunidades sucesoriales", comprendidas por su referencia a los agentes ascendientes que actuaron en la inscripción original de las tierras. Siguiendo a González y Gundermann (2009), estas comunidades comprenden a un colectivo local que posee, administra y usufructúa de manera mancomunada, de acuerdo a derechos sucesorios transmitidos por vía paterna, un determinado espacio territorial, donde poseen explotaciones ganaderas. En este tipo de colectividades se mantiene una propiedad común o colectiva de la tierra, mientras que el ganado corresponde a propiedad privada, manejado independientemente por los hogares configurados por sus redes de parientes, que interdigitan el altiplano con la ciudad de Arica.

La estancia de Huallancallane se constituyó legalmente en la segunda década del siglo $\mathrm{XX}$. En 1911 se tiene el registro de la primera inscripción del predio por parte de Florentina Condori de Cáceres y sus tres hijas, nacidas de su segundo matrimonio con Asensio Flores: Concepción, 
Plácida y Jacoba Flores Cáceres. Al año siguiente, 1912, fue inscrito el predio solo a nombre de los hijos de Concepción: Dámaso, Santiago, Nieves y Petrona. De ellos, fueron Dámaso y Nieves los que mantuvieron líneas de descendencia en el territorio, quienes se constituyeron en las "cabezas" de los linajes actuales del territorio.

Actualmente, las personas que residen en el predio son once, las que se referencian en una familia extensa que se encuentra radicada principalmente en la ciudad de Arica. Los vínculos con la estancia se mantienen vigentes, formando lo que ha sido denominado como el proceso de "translocalización de las comunidades", esto es, que transcienden a la localidad para su realización colectiva (Gundermann, 2001; Gundermann \& Vergara, 2009; González, Gundermman \& Hidalgo, 2014). Los miembros de la comunidad se han expandido por toda la región, estableciendo nuevos vínculos con el territorio propio y el de migración, complejizando y diversificando sus actividades sociales y económicas. Si bien este proceso se aplica a Huallancallane, presenta la característica de que casi todas las personas que residen de forma permanente en la estancia corresponden a adultos mayores, quienes han optado por mantenerse en su lugar de origen y tienen un fuerte arraigo en el pastoreo extensivo. Los desplazamientos y las nuevas relaciones en el territorio regional son establecidas principalmente por sus hijos, siendo ellos la conexión entre el mundo andino tradicional y la modernidad occidental, siguiendo las ideas de Urbano (1992). Es a través de aquella generación que se manifiesta la "translocalidad". Esto ha provocado una dificultad para el sostenimiento de la práctica del pastoreo, la principal actividad económica de la estancia y del colectivo residente, en un contexto de desestructuración de sus lógicas y conocimientos tradicionales.

En la estancia existen cinco unidades domésticas, las que se encuentran establecidas en cinco sectores. Estos son los lugares de residencia principal y que actualmente son ocupados durante casi todo el año, ya que los desplazamientos hacia otros sectores temporales son cada vez menos recurrentes.

Figura 1. Patrón residencial según grupos de descendencia

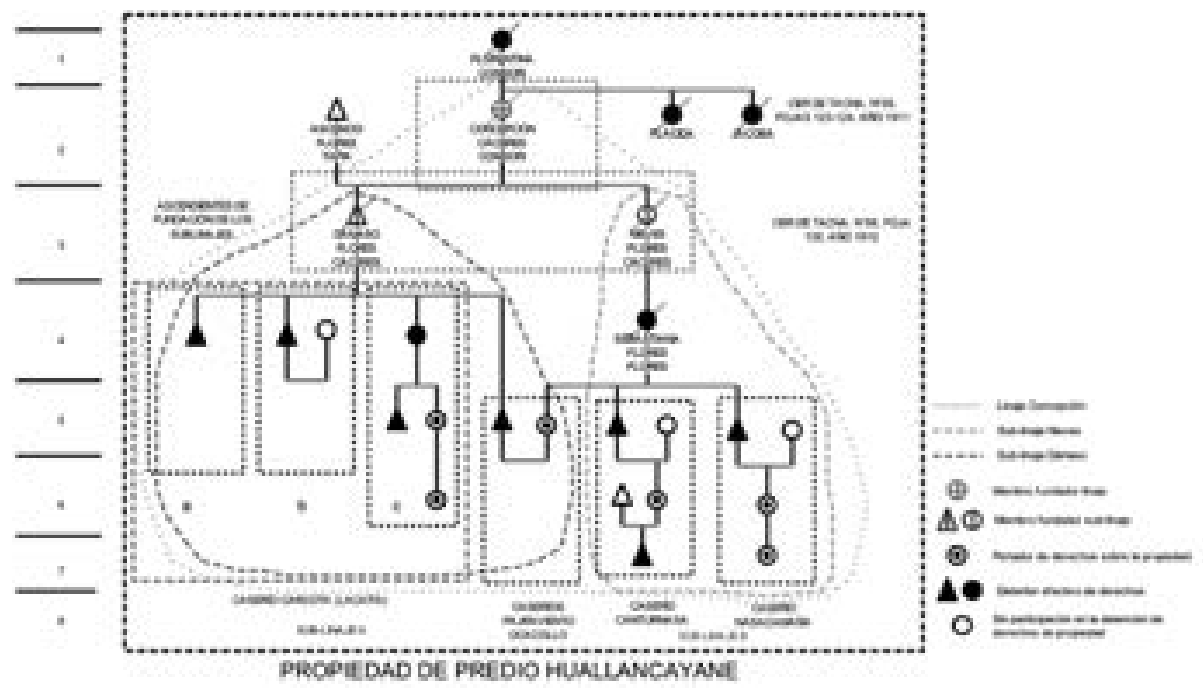

Fuente: Cerna, Samit \& Fradejas (2013). 


\section{Sistema de pastoreo}

El desplazamiento constante y extensivo es una característica del sistema de pastoreo en el ecosistema del altiplano (Flores, 1983; Flores \& Tapia, 1984; Göbel, 2002; Gundermann, 1984; Kuznar, 1994; Nielsen, 2002; Palomino, 2012). En función a las necesidades forrajeras del ganado, los pastores realizan desplazamientos estacionales a sectores donde mantienen otras residencias transitorias, para aprovechar los pastizales de la temporada, tiempo propicio que permite la renovación de forraje en otros sectores, hacia donde luego se desplazarán con el ganado. Por tanto, es común que los pastores tengan una residencia matriz y diferentes residencias temporales, de características rudimentarias, con los elementos básicos para cocinar y dormir. Al respecto, un actor del sector explica que durante el año vive en tres lugares:

\footnotetext{
"Nosotros pastoriamos acá [Pajraviento] dos familias, de acá del río pa este lado pastoriamos nosotros, del río al frente pastorea el Isidro y Carmelo Flores, que son dos hermanos" (V.C. 35 años).
}

Igualmente, en el sector superior del bofedal llamado Ocacollo, a los pies del cerro Comunane, tiene una vivienda, la que se definió por arreglos de parentesco:

"También mi primo Galo, y al frente vivo yo también, pa este lado al frente tengo casita [Ocacollo]. Es que nos cambiamos de lugar, una temporada estamos abajo [Carcota], otra temporada estamos acá y otra temporada estamos más arriba, por falta de pastizales también" (V.C. 35 años)

Así, en su sistema de pastoreo se articulan los sectores de Carcota, Ocacollo y Pajraviento, durante una misma temporada. Esta descripción es similar al resto de los actores entrevistados, quienes también mantienen residencias temporales en diferentes lugares. De esas residencias, se desplazan a las zonas más alejadas del bofedal, a viviendas en los sectores secos. Por ejemplo, otro entrevistado explicaba cómo funcionaba hace unas décadas este sistema de manera general:

\footnotetext{
"Abajo se llama Achuta, ese un caserío antiguo también, ahí un mes, después bajaban para otro lado, igual un mes, después allá en Patilluta que dijimos donde Víctor vive, ahí otro mes, otra vez Conturnasa, después aquí se llama Jurguahue, ahí también, así rondaban antes" (I.F. 67 años).
}

Por tanto, es dable concebir que el motivo que guía los desplazamientos al interior del territorio predial, es la necesidad de alimentar al ganado de acuerdo a la disponibilidad de los recursos forrajeros. Con este propósito, los actores reconocen dos sectores diferenciados del territorio, "de bofedal" y "de cerro" o "de seco". El primero corresponde al pastoreo que se realiza al interior y en las inmediaciones del bofedal, contando con una provisión regular de agua. Mientras que el segundo, se refiere a los lugares áridos de los cerros y las pampas, donde el ganado se alimenta de diversas vegetaciones que brotan especialmente tras las lluvias de verano. Los meses privilegiados para utilizar el "seco" son desde marzo hasta noviembre, desplazándose entre diversas zonas de pastizales, regresando a los sectores cercanos "de bofedal" entre los meses de diciembre y febrero. Las fechas, por supuesto, admiten variaciones de acuerdo a una evaluación de las condiciones específicas del clima que realizan los pastores durante la temporada. Cabe precisar que estos espacios de pastoreo deben entenderse complementarios, ya que ofrecen distintos tipos de forraje durante el año, siendo indispensable 
para cada pastor contar con acceso a lugares en ambos tipos de sectores.

Debido a que el bofedal es el espacio de ocupación común entre los habitantes de la estancia, su utilización ha sido normada en base a acuerdos consuetudinarios, los que son respetados por sus miembros según su pertenencia en las diferenciaciones de familias. Un actor lo describe así:

\begin{abstract}
"Hay una costumbre, por ejemplo si el día lunes y martes yo echo los animales al bofedal, la otra familia lo lleva para otro lado, miércoles y jueves así. Es como por costumbre, o también de repente la familia que primero echa al bofedal, el otro ya sabe que ese día tiene que echarlo para otro lado, es como algo amistoso, por acuerdo" (F.C. 32 años).
\end{abstract}

Consecuentemente, existe un pacto implícito de utilización del bofedal, el que funciona con relativa flexibilidad debido a que la coordinación resulta difícil por el patrón disperso y distanciado de asentamiento de la estancia. Como es posible apreciar, la territorialidad expresada por los pastores se basa en la movilidad con residencias temporales y dispersas, comprendida predialmente.

\section{Conflictos}

\section{La constitución del grupo}

Actualmente, el sistema de pastoreo presenta dificultades para su reproducción local. Uno de aquellos problemas se relaciona con las transformaciones experimentadas en las estructuras familiares de los pastores, las que, a su vez, tienen estrecha relación con los cambios en el régimen de propiedad de la tierra.
Los habitantes de la estancia probablemente formaban una familia extensa asociada al pastoreo que permitía el bofedal de Huallancallane, quienes mantenían relaciones de parentesco con otros sectores del altiplano, especialmente Cosapilla, lugar que desde tiempos coloniales había funcionado como centro cívico y religioso de sus habitantes. Esta situación se comenzó a modificar al abrirse la inscripción de las propiedades de manera privada bajo la administración chilena, fragmentándose la localidad de Cosapilla en una gran cantidad de estancias particulares.

Ese fue el caso de Huallancallane, conformada como una estancia en 1911 cuando el predio fue inscrito a nombre de Florentina y sus tres hijas, momento en el que comenzó una línea de descendencia que es reconocida como el actual linaje fundacional de la comunidad, con lo que se fueron perdiendo los vínculos que unían esta familia extensa a otros sectores del altiplano, especialmente Cosapilla. Sin embargo, hasta entrado el siglo XX todavía eran visibles estas relaciones. Así lo describe un actor al ser consultado por la existencia de festividades religiosas en la estancia,

\footnotetext{
"Ah, anteriormente Cosapilla, ese pueblo de nosotros po. Este es una estancia no más (...) Y ahora ya no, se murió fiesta. Antes había mayordomo" (I.F. 67 años).
}

Otro actor también dejaba clara la relación con Cosapilla,

"Bueno, no sé en realidad, no sé por qué, todos mis hermanos han estudiado en Cosapilla, no sé si en hectáreas o en kilómetros será más cerca [que Visviri], pero por ejemplo mi mamá estaba inscrita en la junta vecinal de Cosapilla, siempre hemos pertenecido a Cosapilla, entonces por eso nos matricularon a Cosapilla y todos estudiamos en Cosapilla" (F.C. 32 años). 
Conviniendo en un proceso de diferenciación general de predio/familia extensa, la estancia, como unidad sociológica, experimentó procesos internos de fisión. Desde el momento de su fundación, la estancia fue fragmentándose de acuerdo a la descendencia de los hijos de Dámaso (7 descendientes: 3 hombres, 4 mujeres) y Nieves (3 descendientes: 1 hombre, 2 mujeres). En base a arreglos de tipo consuetudinario, se estableció una zonificación del territorio de acuerdo a las áreas de ocupación tradicional de los descendientes. Así, tras extensos procesos de ajuste territorial y demográfico, la estancia actualmente está dividida en cinco grandes sectores, los que son utilizados por cinco unidades domésticas. Estas cabe entenderlas como las unidades básicas de producción de la estancia, siendo las que efectúan concretamente el pastoreo en el altiplano y se encuentran mediando entre las relaciones de las familias nucleares y la familia extendida, observación que han imputado también para otros casos Göbel (2002) y Palomino (2012). En este caso, las cinco unidades domésticas aglutinan a familias nucleares surgidas de los hijos de Dámaso y Nieves (Isidro, Carmelo, Celestino, Carlota, Julia, Constancio). Entre las familias, por cierto, adquieren una centralidad los pastores que se mantienen residiendo en la estancia.

Estas divisiones en unidades domésticas con espacios sectorizados para el pastoreo han creado una dificultad para acceder al recurso forrajero disponible en el territorio, ya que hoy se ocupan de manera paralela cada uno de los distintos sectores que conforman la estancia. Según un actor, haciendo una comparación con el sistema manejado décadas atrás,
"Guardaban antes pasto po, no como ahora, ahora no po, somos harto ya, entonces todos tenemos ganado, ya no podemos guardar así. Antes poco ganado dice que tenía po, así una familia no más po; Nieves, Dámaso, por un papá, por una mamá ¿ve? Por eso que vivía así, ahora no po, ya Nieves tenemos, otros hijos, hijas, estamos más hijos. Más gente po, aportó familia" (I-F. 67 años).

De esta manera, al aumentar considerablemente la familia, y la consiguiente subdivisión del territorio, se fue ejerciendo cada vez una mayor presión sobre el forraje disponible. Esto, porque a cada familia se le debía asegurar el acceso al bofedal y pastizales para mantener su ganado. En las actuales condiciones de subdivisiones, el sector de cada familia resulta insuficiente por sí mismo para mantener a los animales, lo que obliga a un movimiento constante al interior del territorio, como nota el actor anterior,

"con esa parte no logra abastecer completamente, por eso que cambiamos, otro mes allá, otro mes allá" (I-F. 67 años).

Para sortear esta dificultad, hace algunas décadas se daba una coordinación grupal entre todos los miembros que tenían ganado,

\footnotetext{
"Nosotros de este tiempo sabemos estar abajo, porque sabe estar lloviendo, enero bajamos nosotros, vivimos abajo todos abajo, y acá arriba reservamos pasto. Pero ahora no, nosotros no respetamos, otros viven arriba hace comer todo, no reservamos, no como antes, antes era más bien unidos. Mi tío, Basilio Flores, ordenaba a nosotros, 'a ver este mes vamos a bajar todos abajo', ya bajamos abajo todos, después dice que 'ahora vamos a subir', y subimos también, después por parte [ocupamos] también arriba" (I-F. 67 años).
} 
Tras el fallecimiento de Basilio Flores, dejaron de tener esta práctica, revelando una matriz egocentrada de la red de parientes. Cada familia se hizo cargo del sector que tradicionalmente le correspondía, pero sin realizar acuerdos para trasladarse conjuntamente a determinados sectores y así aprovechar coordinadamente los recursos. Esta situación ha provocado una dificultad para acceder a pastizales de manera diferenciada en el año, ya que en estos momentos,

"sus sobrinos, nietos ya no reconocen, ya no te reservan. Así estamos viviendo" (I-F. 67 años).

Un factor importante que permite entender esta situación es la dimensión de los cambios en los mecanismos para establecer los grupos de descendencia. La forma tradicional de acceso a las tierras en las sociedades pastoriles del altiplano ha sido por línea paterna, hipotecando el derecho de las mujeres a través de la exogamia por vía femenina, debiendo buscar su complemento en otros sectores del altiplano, en este caso en otras estancias, donde la mujer re-localiza su residencia con el marido y/o pareja de hecho (Cerna, Samit \& Fradejas 2013; González, 1997).

Con los cambios estructurales en el régimen de propiedad consuetudinario, el género ya no constituye una exclusión para acceder a los derechos hereditarios sobre la propiedad. La norma unilineal de parentesco fue modulada por el régimen bilateral del sistema nacional. Las sociedades pastoriles, producto de las migraciones a la ciudad y del mayor conocimiento del sistema jurídico nacional, se han visto re-formuladas en sus principios socio-estructuradores ante el acceso a la tierra. Un actor, a quien en algún momento otros miembros de la comunidad le denegaban su derecho a las tierras por ser hijo de madre soltera, explicaba que a él le rechazaban porque,

“'Hija soltera no tiene derecho' dice. Era así dicen, antes. Y no reconocía como heredero a mujeres, solamente hombres. Pero después había muchos problemas, ahí salió otra ley, mismo ha dicho, casado o soltero (...) Antiguo sipo, después que sufrieron mucho, el que no legítimo, soltero, sufría po sin tener derecho ni donde parar" (I-F. 67 años).

Así, una manera que tenían los grupos pastoriles para controlar la presión demográfica, y por tanto sobre los recursos, se fue alterando paulatinamente. En paralelo, la tierra fue cambiando de giro, desde residencial productivo a uno de valoración comercial, incorporándose los miembros de la familia extensa. En el caso de Huallancallane, se registran más de cuarenta personas con legítimos derechos sobre la propiedad colectiva de la tierra. Comenta el actor anterior,

"Primero empezó de poco familia, después más más más y ahí creció la familia, ahora somos como 30 o 40 familia, mucha gente" (I-F. 67 años).

Esto se traduce en que los rebaños de cada unidad doméstica están conformados por animales cuya propiedad es compartida por una gran cantidad de personas. Por ejemplo, sostiene el actor que,

\footnotetext{
"Nosotros tenemos con mis hijas más, con mis hijos, con toda la familia" (I-F. 67 años).
}

Otro actor, nota que,

"No son todos de una persona, son de toda la familia" (F.C. 31 años). 
Esta característica ha sido observada para la totalidad de los rebaños. El conjunto está compuesto por ganado, en mayor o menor cantidad, perteneciente a distintos miembros de la familia. Situación que aumenta la presión sobre los recursos forrajeros.

Con el transcurso del tiempo, las ramas familiares se han ido distanciando, a pesar de constituir y declarar que forman una "comunidad". Las instancias de comunicación son escasas, cada línea de descendencia ha seguido caminos propios, muchas veces tomando decisiones que afectan al conjunto de la estancia sin consultar a los otros miembros de la comunidad. Pensamos que esto tiene sus fundamentos en dos procesos: 1 . la misma fragmentación de la estancia ha provocado disputas por el territorio; y, 2. la masiva conversión de las familias al evangelismo ha eliminado las antiguas formas comunitarias de resolución de problemas, las que se daban en torno a las festividades religiosas católicas que actualizaban el sentido comunitario de la estancia. Así, se observa una falta de instancias comunitarias, provocando una mayor centralidad de las unidades domésticas como entidades de continuidad y cambio de las relaciones sociales y productivas.

A este conjunto de factores, se debe agregar uno de características locales. El territorio de Huallancallane presenta algunas dificultades en comparación con otras estancias del altiplano, en alusión a la percepción de los agentes, lo que sintetiza un actor local de la siguiente manera,

\footnotetext{
"Se hace poco el terreno porque acá no tiene bofedal bueno, puro espina, como sarro, en aymara se llama 'colpa', ese es amargo, levanta como sarro pue`, el bofedal tiene blanco no más. Entonces ese es un problema. Después acá yerba, ese sale como
}

alfalfa, está malo, hace curar llamo, se muere total pue', en aymara se llama 'garbanza'. Entonces ese es otro malo. Después aquí este sector el terreno es malo, porque puro barranco, ahí caen ganado, ahí mueren. Entonces hay tres problemas en este lugar" (C.F. 70 años).

Se observa que aspectos como el relieve irregular, el crecimiento de flora valorada como perniciosa para los animales y el hecho de tener un bofedal de mala calidad, dificultan la actividad pastoril. A esto se suma el hecho que existe un único bofedal en el territorio, que debe ser compartido entre las familias, lo que reduce la superficie en condiciones aptas para el pastoreo.

Estas características de la estancia son relevantes, ya que el territorio, si bien es extenso, no permite abastecer adecuadamente el ganado de todas las familias, el que actualmente,

"debe ser más menos como unas 1.500 cabezas entre todos" (V.C. 35 años).

\section{Tierras comunitarias}

Otro de los problemas relevantes para los pastores de Huallancallane, es el relacionado con la propiedad de la tierra en función a sus diferenciaciones internas. Esto ha llevado a que sigan trayectorias de regularización segmentarias, referente a los descendientes de Dámaso y a los de Sebastiana. En este orden, se pudo inscribir el terreno que estaba a nombre de Concepción Cáceres, pero no han podido demostrar que Dámaso y Nieves, quienes son las cabezas de los actuales linajes, eran hijos de Concepción, debido a que no se cuenta con registros legales de 
su padre Asencio Flores, ni certificados de inscripción o de nacimiento de los hijos. Esto ha gatillado la diferenciación del grupo, sobre la base de ser una propiedad privada.

Luego de algunos conflictos entre las familias por los derechos de herencia sobre la propiedad de la tierra, estas han llegado a acuerdo para inscribirla a nombre de la comunidad legalmente reconocida. Sin embargo, esto ha tenido complicaciones, encontrando trabas en los organismos dependientes del Ministerio de Bienes Nacionales, impidiendo que el expediente llegue a su tramitación final. El principal argumento presentado por Bienes Nacionales para denegar la inscripción de la propiedad a nombre de los comuneros, es la extensión del predio en relación a los habitantes de la estancia, considerando que la cantidad de hectáreas es excesiva para la cantidad de habitantes de la estancia. Esto demuestra la incomprensión de las autoridades gubernamentales pertinentes respecto al sistema de pastoreo y las dinámicas familiares actuales de los pastores de Huallancallane. El análisis de la actual relación entre unidades domésticas ganado - medio ambiente, expresa la dificultad para mantener este tipo de vida pastoril en el altiplano.

Un actor lo manifestaba de la siguiente manera,

"Yo me acuerdo que yo crecí viendo cómo regularizar el título del territorio. Entonces ya cuando yo cumplí 20 años empecé como a meterme un poco y ya he hecho harto, todos los aportes que pueda, ir a Bienes Nacionales, Conadi, a todos lados; y piensan que porque el predio es grande, lo toman como en el sur, pero las propiedades tienen otro punto de vista, entonces dicen 'pero cómo si son tantas hectáreas le vamos a dar a tres familias, cuatro familias, tantas hectáreas'. En el sur con una hectárea, no se poh, tienen una crianza de tantas vacas, y yo les digo la realidad acá es distinta porque acá uno no puede plantar una hectárea de forraje, imposible. Piensan como que fuera un terreno en el valle. Son terrenos que prácticamente no sirven mucho, no se puede sembrar, o sea crece el pasto para la crianza de los animales, no sirve para nada más, no ven ese lado, las autoridades no ven esa forma" (F.C. 31 años).

Esta situación, junto con demostrar la limitada capacidad de las autoridades para entender y aceptar las especificidades económicas y culturales de los pastores de Huallancallane, vulnera sus derechos como miembros pertenecientes al pueblo aymara, uno de los pueblos indígenas reconocidos por el Estado chileno. En este contexto, existe una necesidad de apercibir la tierra como un aspecto esencial, conforme la legislación internacional y que ha sido ratificada por el Estado chileno, comprometiéndose a cumplir con sus dictámenes, como la Declaración de las Naciones Unidas sobre los derechos de los pueblos indígenas (2007) o el Convenio 169 de la Organización Internacional del Trabajo (ratificado en 2008).

El sistema legal-jurídico nacional, a pesar que formalmente debe adecuar sus normas al sistema tradicional de ocupación del territorio de los pueblos indígenas, en esta oportunidad los margina del derecho a la posesión de su tierra. En términos concretos, la situación descrita ha sido perniciosa para el mejoramiento de las condiciones de habitabilidad y de producción en la estancia, ya que para postular a recursos, estatales o de otro tipo, requieren poseer el título de la propiedad y/o arriendo. Esto provoca que los beneficios sean utilizados de manera individual o por unidades domésticas, pero no en beneficio de la comunidad en tanto entidad de derecho colectivo, acentuando el proceso de fragmentación que esta experimenta. 


\section{Modernización y mercado}

Por otra parte, los efectos de la modernización y las presiones del mercado han sido desfavorables para la promoción del sistema de reproducción de pastores locales. A pesar de las mociones por la integración socioeocnómica de la actividad, se ha generado un escenario de pauperización local, que ha dado forma histórica a la emigración de cortes reproductivos de la población rural desde mediados del siglo XX. Esta "fuga" de personas se ha traducido, económicamente, en la disminución de fuerza laboral, la que era destinada principalmente al pastoreo del ganado, así como en la "regionalización" y "translocalización" de la comunidad local, con importantes prolongaciones simbólicas y económicas (Gundermann, 1998, 2001; González \& Gundermann, 2009). En este escenario, la ocupación en las ciudades hace difícil el retorno a las labores productivas de tipo tradicional, por lo que el pastoreo diario es realizado por las personas de edad avanzada que residen en la estancia, sin estar exentos de complicaciones de salud². Por esta razón, algunas familias han optado por contratar pastores indígenas de Bolivia y/o Perú, situación que dificulta la rentabilidad de la actividad ganadera, y supone la adición de complejidad a la plataforma comunitaria que soporta la actividad y su reproducción.

\footnotetext{
"Después en esta edad conseguimos pastor, el pastor tamos pagando 150-200 [mil pesos], porque nosotros ya no vamos a pastiar, mi señora está cansada también, más encima está enferma de rodilla, yo también estoy usando marcapaso, así que ya no pasteo ya, estoy en la casa no más, no puedo subir mucha subida tampoco" (I.F. 67 años).
}

A su vez, la creación de la carretera y el consiguiente decaimiento del ferrocarril Arica-La Paz en la segunda mitad del siglo XX, provocó una coyuntura desfavorable al disminuir la demanda de carne y carbón que era suministrada por los pastores. Las llamas, que eran utilizadas como animales de carga para llevar el carbón de queñuas y llaretas a las estaciones de los trenes, dejaron de ocuparse para esos fines. A su vez, el transporte de mercancías a largas distancias que se realizaba con llamas también se vio afectado. Esto provocó el retraimiento del sistema local de relaciones que soportaba el manejo ganadero, hasta su arista de auto-subsistencia en las unidades domésticas.

Desde ese momento el ganado solo sería rentable por su venta de carne y lana. Esta forma de integración al mercado ha limitado las posibilidades de desarrollo de los pastores de Huallancallane. La competencia con los productores de lana de los países vecinos es muy fuerte, especialmente con los de Perú, quienes tienen una vasta y extensa trayectoria en la producción de fibra camélida. Por tanto, actualmente, acumulan la lana en sus hogares y cuando esta adquiere un "buen precio", es vendida a los productores peruanos en la feria del Tripartito de Visviri. Aun así, el buen precio es una cifra baja considerando el largo proceso que implica la obtención de los vellones de lana.

Por su parte, el consumo de carne ha estado sujeto a vaivenes en relación a los contextos regionales de la economía y, considerando la percepción de los entrevistados, esta se ha reducido desde la década de 1960. A esto se debe agregar que su comercialización se restringe cada vez más por parte de las autoridades gubernamentales, debido a que los pastores no cuentan con los permisos sanitarios establecidos por el Servicio Agrícola y Ganadero (SAG), limitándose a vender en cuotas bajas para eventos rituales, festividades 
religiosas o recurriendo a ventas de manera ilegal. Así, se observa que la tenencia de ganado se ha mantenido principalmente como fuente de consumo familiar, entre la estancia y la ciudad, y producto de la demanda ocasional o específica de otras localidades de raigambre indígena, especialmente las precordilleranas.

La situación de inestabilidad se agrava al considerar que en esta estancia la crianza de llamas es muy superior a la de alpacas, principalmente debido a las condiciones específicas que presenta el territorio predial: un solo bofedal y de mala calidad que debe ser compartido por todas las familias. Por este motivo, los pastores de Huallancallane se ven impelidos a mantener mayor proporción de llamas, ya que estas son animales de cerro antes que de bofedal. Así, la mayor cantidad de ganado está constituido por llamas, las que con el transcurso del tiempo han perdido la importancia económica que tenían por su capacidad para movilizar carga, la que fue quedando en desuso debido a los cambios en los medios de transporte. Por tanto, su producción ganadera se destina principalmente a la venta de carne, lo que, en las actuales condiciones, no resulta un negocio lucrativo.

\section{Consideraciones finales}

En este artículo, desde un enfoque antropológico e histórico, se han abordado antecedentes etnográficos sobre las prácticas sociales vinculadas a la actividad de pastoreo en una localidad del extremo norte de Chile, que informan aspectos de los cambios que esta ha experimentado en el siglo XX. Desde el ángulo teórico de la agencia social y ecológica, y producto de tensiones tanto internas como externas, se ha podido apreciar que las sociedades pastoriles han experimentado reformulaciones estructurales, desarrollando mecanismos adaptativos que les han permitido enfrentar nuevos contextos de complejización interna y externa, conforme la instalación de estrategias de reproducción sociocultural y comunitaria. Estos procesos de trasformación se han acelerado en las primeras décadas del presente siglo, llevando a las poblaciones locales a establecer modos de relacionamiento con la sociedad mayor para mantener vigente la actividad pastoril, hasta el momento única actividad económica sustentable en las condiciones de su medio geográfico.

En este contexto, señalamos que el caso de Huallancallane representa los márgenes de la sociedad nacional. Su expresión está representada por la localización en una zona rural de altura, en la frontera con Bolivia, en un espacio andino que fue pauperizado por los Estados republicanos, dejando en la liminalidad del territorio nacional a esta población pastoril, sin considerar su forma de vida en constante movilidad que atravesaba los actuales límites fronterizos. Esta frontera también presenta una expresión ideológica. La fragmentación del territorio ocurrió con la inscripción de las tierras en los Registros Conservadores de Propiedad a comienzos del siglo XX, durante la administración chilena de la actual región de Arica-Parinacota, siendo el año 1911 el momento de inicio de la memoria genealógica de los actuales comuneros de Huallancallane, cuando fue inscrita la tierra y se formó la estancia sucesorial. De acuerdo a la forma de vida pastoril, el territorio de la estancia presenta extensiones discretas, $y$, si bien se ha mantenido su patrón de ocupación de asentamientos múltiples, estos son mucho más restringidos, de tipo local, en virtud de la ocupación del espacio al interior de 
la estancia. Para los pastores de Huallancallane, su función de mediadores (Medinaceli, 2002) o de integradores (Núñez \& Dillehay, 1995) con el "mundo de afuera" ha cambiado para reducirse a un ámbito de acción limitado y, a su vez, conflictivo.

El área discreta de la estancia ha mostrado sus limitaciones ante las transformaciones sociales, económicas y demográficas de las últimas décadas. En la medida que el sistema de herencia y acceso a la tierra ha experimentado cambios, combinando aspectos consuetudinarios y del sistema jurídico-legal chileno, el espacio de pastoreo está resultando insuficiente para la reproducción social de la comunidad. Por otra parte, las nuevas estructuras familiares y descendencia de Huallancallane, presionan por la ampliación de los derechos sobre el territorio, tensionando disputas al interior de las familias. Esto se ha hecho efectivo mediante la conformación de rebaños que presentan una gran diversidad de propietarios, todos miembros de las diferentes unidades domésticas. En relación a la condición etaria de los pastores y la falta de mano de obra en el altiplano, el sistema de pastoreo también está experimentando transformaciones que dificultan la rentabilidad de la actividad productiva. A su vez, la débil integración al mercado, cuya inestabilidad se refleja en la fuerte dependencia externa de sus productos, carne y lana de camélidos, tiende a la desestructuración de las estrategias locales de subsistencia.
A pesar de estos conflictos con los que actualmente están lidiando los comuneros de Huallancallane, los organismos pertinentes del Estado chileno desconocen su propiedad sobre la tierra, problema derivado de la contradicción entre los sistemas normativos tradicionales de acceso a la tierra de las poblaciones aymara del altiplano y las occidentales del derecho positivo. La situación de subordinación del sistema consuetudinario y propiedad colectiva indígena frente al sistema jurídico nacional dificultan la comprensión del problema que enfrentan los comuneros de Huallancallane. El desconocimiento de la forma de vida de los pastores altiplánicos los margina y los sitúa en las fronteras de nuestra sociedad, geográfica y simbólicamente.

Este análisis corresponde a un estudio de caso, específicamente centrado en Huallancallane. Una muestra más amplia del espectro de comunidades del altiplano puede arrojar conclusiones extrapolables. Consideramos que estos diagnósticos son necesarios para definir ámbitos de acción que permitan abordar los problemas señalados, y así evitar la pérdida de una actividad que ha sido mantenida a través del tiempo de manera persistente, a pesar de los conflictivos escenarios, por los pastores altiplánicos. 


\section{Notas}

${ }^{1}$ La denominación de "estancia" adquiere distintos significados según la zona o región donde se utilice. Para este caso hemos utilizado como se entiende en el altiplano chileno. Para analizar

\section{Referencias bibliográficas}

Cerna, C. \& Samit, S. (2013). "Migración interna rural-urbana, movilidad y redes sociales translocales de las comunidades aymara del extremo norte de Chile. Algunos antecedentes etnográficos desde la región de Arica y Parinacota". Actas del XXIX Congreso Latinoamericano de Sociología.

Cerna, C., Samit, S. \& Fradejas, I. (2013). "Grupos de descendencia y propiedad de la tierra aymara en el altiplano del extremo norte de Chile (Región de Arica y Parinacota)". Revista Austral de Ciencias Sociales, № 25.

Castro, L. (1997). "El campesinado altoandino del Norte de Chile". En El Altiplano. Ciencia y conciencia en los Andes. II Simposio Internacional de estudios altiplánicos, 19-21 de Octubre de 1993. Arica, Chile.

(2006). "Comunidad territorial indígena, gestión de recursos hídricos y derechos colectivos". Paper presented at the Congreso Internacional WALIR Pluralismo legal, reforma hídrica y políticas de reconocimiento. Cusco, Perú.

(2014). "La conformación de la frontera chileno-boliviana y los campesinos aymaras durante la chilenización (Tarapacá, 18951929)". Historia Crítica, № 52.

Díaz, A. \& Ruz, R. (2009). "Comuneros andinos en la administración chilena (Arica, 1880-1929)". Revista de Historia Social y de las Mentalidades, № 13.

Flores, J. (1983). "El ecosistema del pastoreo andino en las tierras altas de los Andes Centrales". En Sobrevivencia campesina en ecosistema de altura. Vol II. Santiago: CEPAL-PNUMA.

Flores, J. \& Tapia, M. (1984). Pastoreo y pastizales de los Andes del Sur del Perú. Lima: Instituto Nacional de Investigación y Promoción Agropecuaria.

Göbel, B. (2002). "La arquitectura del pastoreo: Uso del espacio y sistema de asentamientos en la Puna de Atacama (Susques)". Estudios Atacameños, № 23.

González, H. (1997). "Disponibilidad, acceso y sistemas de tenencia de la tierra entre los Aymaras del altiplano de la I región de Tarapacá". En El Altiplano. Ciencia y conciencia en los Andes. II Simposio Internacional de estudios altiplánicos, 19-21 de Octubre de 1993, Arica, Chile.

González, H. \& Gundermann, H. (2009). "Acceso a la propiedad de la tierra, comunidad e identidades colectivas entre los aymaras del norte de Chile". Chungara, Revista de Antropología Chilena, № 41 (1). otras formas de entender este concepto ver: Göbel (2002), Flores (1983).

${ }^{2}$ Tres de los entrevistados presentaban problemas de salud que impedían realizar adecuadamente el pastoreo: uno, debe cuidarse porque tiene marcapaso; otro, problemas a las articulaciones; y un tercero, problemas a las rodillas que le dificulta caminar en los cerros.

González, H. \& Ruz, R. (2015). "Fe en el papel: la inscripción del dominio de las tierras de comunidad en el altiplano chileno". Diálogo Andino, № 46.

González, H., Gundermann, H. \& Hidalgo, J. (2014). Comunidad indígena y construcción histórica del espacio entre los aymara del norte de Chile. Chungara, Revista de Antropología Chilena, № 46.

Gundermann, H. (1984). "Ganadería Aymara, Ecología y Forrajes: Evaluación regional de una actividad productiva andina". Chungara, Revista de Antropología Chilena, № 12.

(1998). "Pastoralismo andino y transformaciones sociales en el norte de Chile". Estudios Atacameños, № 16.

(2001). "Procesos regionales y poblaciones indígenas en el norte de Chile. Un esquema de análisis con base en la continuidad y los cambios de la comunidad andina". Estudios Atacameños, № 21.

Gundermann, H. \& y Vergara, J. (2009). "Comunidad, organización y complejidad social andinas en el norte de Chile". Estudios Atacameños, № 38 .

Kuznar, L. (1994). "Pastoreo en las sierras altas de la zona Centro Surandina: el caso de Moquegua, Perú”. Diálogo Andino, № 13.

Medinaceli, X. (2005). "Los pastores andinos: una propuesta de lectura de su historia. Ensayo bibliográfico de etnografía e historia". Bulletin de I'nstitut Francais d'Études Andines, № 34.

Nielsen, A. (2002). "La complementariedad entre los pastores del altiplano de Lípez (Potosí, Bolivia)”. Mundo de Antes, № 3.

Núñez, L. \& Dillehay, T. ([1979] 1995). Movilidad giratoria, armonía social y desarrollo en los Andes Meridionales: Patrones de Tráfico e interacción económica. Antofagasta: Universidad Católica del Norte.

Ossio, J. (1982). "Estructura social y parentesco en la Antropología sobre el área andina." Anuário Antropológico, № 80.

Palomino, T. (2012). "Unidad doméstica altoandina y crianza de camélidos sudamericanos". Investigaciones Sociales, № 29.

Postigo, J., Young, K., \& Crews, K. (2008). "Change and Continuity in a Pastoralist Community in the High Peruvian Andes". Journal of Human Ecology, № 36.

Ruz, R. (2009). "De tierras incultas y mostrencas a propiedad fiscal. Categorías estatales para la definición de las tierras de uso colectivo en la frontera norte chilena S. XIX - XX". Si somos americanos. Revista de Estudios Transfronterizos, № 9.

Ruz, R. \& González, H. (2014). "Estado peruano, liberalismo y tierras indígenas en la precordillera de Arica (1854-1880)". Si Somos Americanos. Revista de Estudios Transfronterizos, № 14. 
Salomon, F. (2012). "Etnología en un terreno desigual: encuentros andinos, 1532-1985. En Degregori, C., Sendón, P. \& Sandoval, P. (Eds.) No hay país más diverso. Compendio de la antropología peruana II. Lima: IEP Ediciones.

Sendón, P. (2003). "Cambio y continuidad en las formas de organización social de las poblaciones rurales del sur peruano. El caso de la comunidad campesina de Phinaya." Debate Agrario, № 36 .

(2008). "Organización social de las poblaciones pastoriles de los Andes del sur peruano: hacia un balance comparativo de un aspecto omitido". En Dalmonte, G., Fulcrand, B. \& Gómez, R. (Eds.) El problema agrario en debate. Lima: SEPIA.

(2006). "Ecología, ritual y parentesco en los Andes: notas a un debate no perimido". Debate Agrario, № 40-41.
(2012). "Estudios de parentesco y organización social en los Andes. En Degregori, C., Sendón, P., \& Sandoval, P. (Eds.) No hay país más diverso. Compendio de la antropología peruana II. Lima: IEP Ediciones.

Tomasi, J. (2013). "Espacialidades pastoriles en las tierras altoandinas. Asentamientos y movilidad en Susques, puna de Atacama (Jujuy, Argentina)". Revista de Geografía Norte Grande, № 55.

Urbano, H. (1992). "Introducción. La tradición andina o el recuerdo del futuro". En Urbano, H. (Comp.) Tradición y Modernidad en los Andes. Cusco: Centro de Estudios Regionales Bartolomé de las Casas. 